June 2007

\title{
Treatment of Kawasaki Disease
}

Andrea Taddio

Institute of Child Health, Trieste, Italy

Carlos D. Rosé

Thomas Jefferson University

Follow this and additional works at: https://jdc.jefferson.edu/pedsfp

Part of the Bioethics and Medical Ethics Commons

Let us know how access to this document benefits you

\section{Recommended Citation}

Taddio, Andrea and Rosé, Carlos D., "Treatment of Kawasaki Disease" (2007). Department of

Pediatrics Faculty Papers. Paper 5.

https://jdc.jefferson.edu/pedsfp/5

This Article is brought to you for free and open access by the Jefferson Digital Commons. The Jefferson Digital Commons is a service of Thomas Jefferson University's Center for Teaching and Learning (CTL). The Commons is a showcase for Jefferson books and journals, peer-reviewed scholarly publications, unique historical collections from the University archives, and teaching tools. The Jefferson Digital Commons allows researchers and interested readers anywhere in the world to learn about and keep up to date with Jefferson scholarship. This article has been accepted for inclusion in Department of Pediatrics Faculty Papers by an authorized administrator of the Jefferson Digital Commons. For more information, please contact: JeffersonDigitalCommons@jefferson.edu. 
port-wine stains through greater vessel heating and deeper vascular injury. ${ }^{2}$ The improved technology targets the heterogeneity in blood-vessel sizes that is characteristic of port-wine stains. ${ }^{3}$

Any study evaluating the response of port-wine stains to treatment should include an analysis based on the location of the anatomical malformation and the patient's age. As compared with other areas of the face and neck, port-wine stains on the center of the face have been shown to respond less effectively to treatment and are more likely to recur. ${ }^{4}$ An aggressive approach to treating infants and young children can also allow for more rapid and complete clearing. ${ }^{5}$

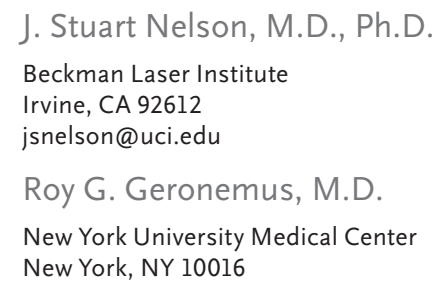

1. Huikeshoven M, Koster PHL, de Borgie CAJM, Beek JF, van Gemert MJC, van der Horst CMAM. Redarkening of port-wine stains 10 years after pulsed-dye-laser treatment. N Engl J Med 2007;356:1235-40.

2. Nelson JS, Milner TE, Anvari B, Tanenbaum BS, et al. Dynamic epidermal cooling during pulsed laser treatment of port wine stain: a new methodology with preliminary clinical evaluation. Arch Dermatol 1995;131:695-700.

3. Barsky SH, Rosen S, Geer DE, Noe JM. The nature and evolution of port wine stains: a computer-assisted study. J Invest Dermatol 1980;74:154-7.

4. Renfro L, Geronemus RG. Anatomical differences of portwine stains in response to treatment with the pulsed dye laser. Arch Dermatol 1993;129:182-8.

5. Geronemus RG, Quintana AT, Lou WW, Kauvar A. High-fluence modified pulsed dye laser photocoagulation with dynamic cooling of port-wine stains in infancy. Arch Dermatol 2000;136: 942-3.
THE AUTHORS REPLY: With ongoing research in medicine, investigating the 10-year follow-up results of any medical treatment inevitably leads to somewhat outdated results at the time of presentation. This is especially the case in a field that is subject to continuous development, such as pulseddye-laser treatment of port-wine stains. As Nelson and Geronemus point out, the results with newer pulsed-dye lasers have been reported to be promising and superior to the results with the laser used in our study. However, to date no controlled comparative studies have shown improved clinical efficacy. Whether the new lasers have improved long-term efficacy remains to be reported; in light of our observation of the recurrence of portwine stains, we certainly hope they do.

No differences or trends in responses to treatment related to the anatomical locations of the port-wine stains were observed in either the original study ${ }^{1,2}$ or the current follow-up study, possibly because of the relatively small number of patients. Furthermore, in the original study, age was shown to have no influence on the response to treatment. Therefore, we refrained from performing age-dependent analyses in the current longterm follow-up assessment.

Menno Huikeshoven, M.D., Ph.D. Chantal M.A.M. van der Horst, M.D., Ph.D.

Academic Medical Center

1100 DE Amsterdam, the Netherlands

m.huikeshoven@amc.uva.nl

1. van der Horst CMAM, Koster PHL, de Borgie CAJM, Bossuyt PMM, van Gemert MJC. Effect of the timing of treatment of portwine stains with the flash-lamp-pumped pulsed-dye laser. N Engl J Med 1998;338:1028-33.

2. Kauvar AN, Geronemus RG. Treatment of port-wine stains. N Engl J Med 1998;339:635-6.

\section{Treatment of Kawasaki Disease}

TO THE EDITOR: In their trial of pulsed corticosteroid therapy for primary treatment of Kawasaki disease, Newburger et al. (Feb. 15 issue) ${ }^{1}$ report that, as compared with placebo, a single pulsed dose of corticosteroid resulted in a shorter initial period of hospitalization but that the total numbers of days of fever and hospitalization, the rates of retreatment, and the coronary-artery outcomes did not differ significantly between the two groups. The use of a single-dose regimen without tapering most likely contributed to their results. A single application of a corticosteroid, even at a high dose, may have a strong but only short-lived effect, which could therefore be associated with a secondary increase in inflammation.

On the basis of nearly 10 years of clinical experience, ${ }^{2}$ we designed a regimen involving a short intravenous course of prednisolone and subsequent oral administration of prednisolone followed by tapering. ${ }^{3}$ In a randomized trial performed to test the effectiveness of the regimen as an adjunct to intravenous immune globulin, the incidences of retreatment and coronary-artery abnormalities within 1 month after the start of treatment were less frequent in the corticosteroid group than in the group receiving immune globu- 
lin alone. Our regimen therefore appears to be more efficacious than the control regimen. Nevertheless, the optimal corticosteroid regimen remains an issue in the primary therapy of Kawasaki disease.

Yoshinari Inoue, M.D.

Tohru Kobayashi, M.D.

Akihiro Morikawa, M.D.

Gunma University Graduate School of Medicine

Gunma 371-8511, Japan

yinoue@showa.gunma-u.ac.jp

1. Newburger JW, Sleeper LA, McCrindle BW, et al. Randomized trial of pulsed corticosteroid therapy for primary treatment of Kawasaki disease. N Engl J Med 2007;356:663-75.

2. Shinohara M, Sone K, Tomomasa T, Morikawa A. Corticosteroids in the treatment of the acute phase of Kawasaki disease. J Pediatr 1999;135:465-9.

3. Inoue $Y$, Okada $Y$, Shinohara $M$, et al. A multicenter prospective randomized trial of corticosteroids in primary therapy for Kawasaki disease: clinical course and coronary artery outcome. J Pediatr 2006;149:336-41.

TO THE EDITOR: Newburger et al. studied the effects of adding intravenous methylprednisolone to conventional therapy for Kawasaki disease. The authors found a significantly lower frequency of coronary-artery abnormalities in the intravenousmethylprednisolone group than in the placebo group within the subgroup of patients who required retreatment with intravenous immune globulin.

The identification of predictors of coronary abnormalities in Kawasaki disease is still problematic. Failure of initial treatment with intravenous immune globulin remains the most consistent risk factor for cardiac abnormalities. ${ }^{1}$ Administration of intravenous methylprednisolone after the failure of initial treatment with intravenous immune globulin does not seem to be effective in reducing the risk of coronary damage, ${ }^{2}$ although the current data suggest that this might not be the case for patients who do not have a response to intravenous immune globulin and who have previously received intravenous methylprednisolone.

Since intravenous methylprednisolone administered as a single dose appears to be safe, ${ }^{3}$ and given our inability to identify a priori the patients who will not have a response to intravenous immune globulin, it seems obvious that the concurrent use of a single dose of intravenous methylprednisolone and intravenous immune globulin may be our best choice at the moment. It is unrealistic to expect that trials powered to show the effectiveness of intravenous methylprednisolone could be accomplished anytime soon.
Andrea Taddio, M.D.

Institute of Child Health

34100 Trieste, Italy

ataddio@yahoo.it

Carlos D. Rosé M.D.

Thomas Jefferson University Wilmington, DE 19803

1. Hashino K, Ishii M, Iemura M, Akagi T, Kato H. Re-treatment for immune globulin-resistant Kawasaki disease: a comparative study of additional immune globulin and steroid pulse therapy. Pediatr Int 2001;43:211-7.

2. Lang BA, Yeung RS, Oen KG, et al. Corticosteroid treatment of refractory Kawasaki disease. J Rheumatol 2006;33:803-9.

3. Sundel RP, Baker AL, Fulton DR, Newburger JW. Corticosteroids in the initial treatment of Kawasaki disease: report of a randomized trial. J Pediatr 2003;142:611-6.

TO THE EDITOR: Although the study by Newburger et al. involved assessment of coronary-artery outcomes with the use of transthoracic echocardiography, we were quite surprised by the inclusion of an example of a coronary aneurysm seen on multidetector computed tomography (CT) in the accompanying Perspective article by Burns. ${ }^{1}$

We and others ${ }^{2,3}$ have shown the efficacy of noninvasive magnetic resonance imaging (MRI) of the heart for both the identification and characterization of coronary artery disease in patients with Kawasaki disease (Fig. 1). Patients with Kawasaki disease require frequent observation over many decades. Given the relatively high doses of ionizing radiation associated with multidetector

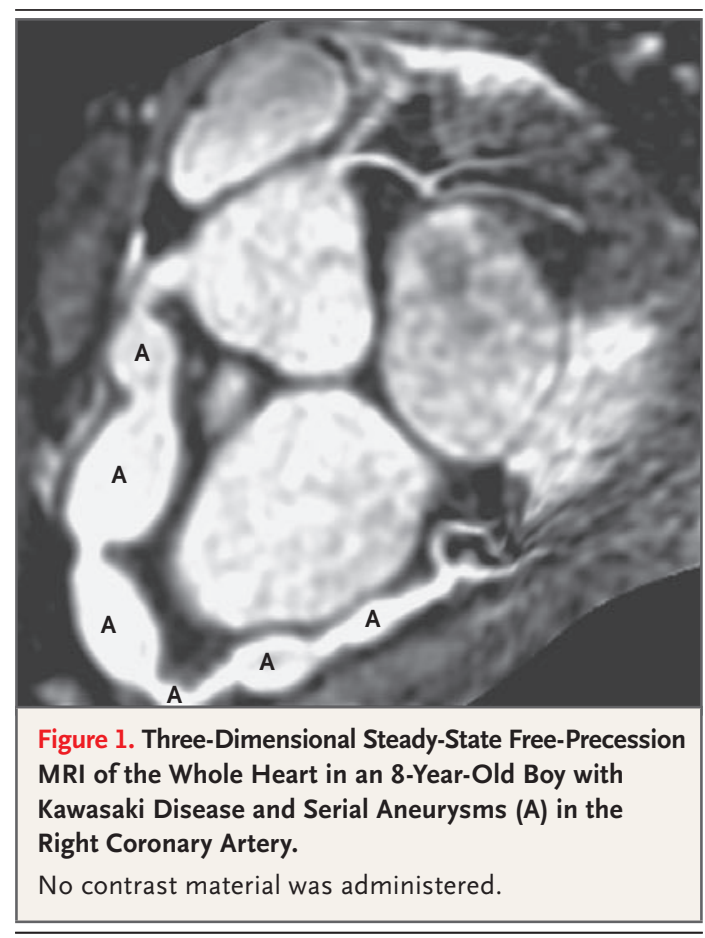


$\mathrm{CT}^{4}$ and the heightened potential for radiationinduced fatal cancer in children, ${ }^{5}$ we believe that, if transthoracic echocardiography is inadequate, these younger patients are best served by the use of coronary MRI.

Gerald F. Greil, M.D.

King's College London

London SEI 9RT, United Kingdom

Warren J. Manning, M.D.

Beth Israel Deaconess Medical Center

Boston, MA 02215

wmanning@bidmc.harvard.edu

1. Burns JC. The riddle of Kawasaki disease. N Engl J Med 2007;356:659-61.

2. Greil GF, Stuber M, Botnar RM, et al. Coronary magnetic resonance angiography in adolescents and young adults with Kawasaki disease. Circulation 2002;105:908-11.

3. Mavrogeni S, Papadopoulos G, Douskou M, et al. Magnetic resonance angiography, function and viability evaluation in patients with Kawasaki disease. J Cardiovasc Magn Reson 2006;8: 493-8.

4. Coles DR, Smail MA, Negus IS, et al. Comparison of radiation doses from multislice computed tomography coronary angiography and conventional diagnostic angiography. J Am Coll Cardiol 2006;47:1840-5.

5. Brenner D, Elliston C, Hall E, Berdon W. Estimated risks of radiation-induced fatal cancer from pediatric CT. AJR Am J Roentgenol 2001;176:289-96.

THE AUTHORS REPLY: Inoue and colleagues describe the results of their open trial using a prolonged course of corticosteroids, which we discuss in our article. We found that clinically significant coronary-artery abnormalities were infrequent in patients in both of our study groups. For this reason, although the optimal corticosteroid regimen may be unknown, we believe that corticosteroid regimens requiring a prolonged course of treatment would be difficult to rationalize for the primary treatment of all patients with Kawasaki disease.

Taddio and Rosé highlight an important question arising from our analyses. Our study was designed to test the hypothesis that the addition of intravenous methylprednisolone to conventional primary treatment of Kawasaki disease would improve coronary-artery outcomes; the study groups had similar overall coronary outcomes. A post hoc subgroup analysis suggested that primary corticosteroid therapy reduced the incidence of coronaryartery abnormalities in a high-risk subgroup of patients in our study who required retreatment with intravenous immune globulin because of persistent or recrudescent fever. However, such subgroup analyses must be interpreted with caution $^{1}$; the literature is replete with subgroup analyses suggesting differential responses to therapy, findings that have been shown to be erroneous in subsequent prospective trials. ${ }^{2}$ Children with Kawasaki disease can be characterized at the time of presentation with respect to their risk of resistance to intravenous immune globulin. ${ }^{3}$ Until further studies are conducted in highrisk patients, we do not believe that corticosteroid therapy should be used in the primary treatment of Kawasaki disease.

Jane W. Newburger, M.D., M.P.H.

Children's Hospital

Boston, MA 02115

jane.newburger@cardio.chboston.org

Lynn A. Sleeper, Sc.D.

New England Research Institutes

Watertown, MA 02472

1. Pfeffer MA, Jarcho JA. The charisma of subgroups and the subgroups of CHARISMA. N Engl J Med 2006;354:1744-6.

2. Rothwell PM. Treating individuals 2: subgroup analysis in randomised controlled trials: importance, indications, and interpretation. Lancet 2005;365:176-86.

3. Kobayashi T, Inoue $\mathrm{Y}$, Takeuchi $\mathrm{K}$, et al. Prediction of intravenous immunoglobulin unresponsiveness in patients with Kawasaki disease. Circulation 2006;113:2606-12.

DR. BURNS REPLIES: Imaging of the coronary arteries is important in the long-term management of aneurysms in patients with Kawasaki disease. Transthoracic echocardiography can be used only to image the proximal arteries, is dependent on a high level of technical skill, and cannot reliably detect stenosis. Advantages of multidetector CT are the assessment of calcification and soft plaque, rapid collection of data, and straightforward interpretation of images. With proper gating to the cardiac cycle and lowering of the heart rate with beta-adrenergic blockade, exposures of approximately $0.67 \mathrm{mSv}$ have been documented for coronary-artery studies of children involving multidetector CT (Larkin G, GE Healthcare: personal communication) (for comparison, one chest radiograph results in exposure to $0.02 \mathrm{mSv}$ ). MRI is safe, but many centers cannot image the coronary arteries with sufficient precision. All these approaches require general anesthesia for young patients, and MRI requires a longer time to capture images than does multidetector $\mathrm{CT}$ and thus increases the time under anesthesia and associated risks. Clearly, this is an area of medicine that is in flux. We look forward to the time when safe, noninvasive imaging methods are widely available at all centers for these children.

Jane C. Burns, M.D.

University of California, San Diego

La Jolla, CA 92093-0830 